$$
\begin{aligned}
& \text { ÉTICA } \\
& \text { PESQUISA ANTROPOLÓG } \\
& \text { A VULNERABILIDADE } \\
& \text { PARTICIPANTES } \\
& \text { TRANSTORNOS MEN }
\end{aligned}
$$




\section{ÉTICA NA PESQUISA ANTROPOLÓGICA: A VULNERABILIDADE DOS PARTICIPANTES COM TRANSTORNOS MENTAIS}

\section{FLÁVIA SIQUEIRA CORRÊA ZELL}




\title{
ÉTICA NA PESQUISA ANTROPOLÓGICA: A VULNERABILI- DADE DOS PARTICIPANTES COM TRANSTORNOS MENTAIS
}

\section{Resumo}

O histórico da regulamentação da ética em pesquisa nos Estados Unidos e no Brasil permite refletir sobre as diretrizes internacionais e nacionais e, particularmente, o Sistema CEP/Conep brasileiro. Embora os sistemas de revisão ética vigentes tenham relegado as contribuições das Ciências Humanas e Sociais, esse campo do conhecimento traz uma reflexão pertinente sobre o processo de obtenção do consentimento livre e esclarecido e as expressões da vulnerabilidade de participantes de pesquisas científicas. O exemplo das pessoas com transtornos mentais partícipes de estudos, ao remeter para as relações de poder existentes entre os ditos loucos e normais, bem como entre as pesquisas biomédica e social, possibilita aprofundar as concepções trazidas por regulamentações metadisciplinares e atentar para especificidades sócio-econômico-históricas de pessoas e/ou grupos de pessoas pertencentes a contextos diversos. O desafio está na busca de consensos na arena científica para que, assim, o debate sobre os cuidados éticos na pesquisa possa tropegamente avançar.

Palavras-chave: Ética na pesquisa antropológica, vulnerabilidade, autonomia, loucura, relações de poder.

\section{ETHICS IN ANTHROPOLOGICAL RESEARCH: THE VULNERA- BILITY OF PARTICIPANTS WITH MENTAL HEALTH DISORDERS}

\begin{abstract}
The history of the regulation of ethics in research in the United States and in Brazil allows us to reflect on international and national guidelines and, particularly, the Brazilian CEP/Conep System. Although the existing ethical review systems have relegated the contributions of the Humanities and Social Sciences, this field of knowledge brings pertinent reflection on the process of obtaining free and informed consent and the expressions of vulnerability of scientific research participants. The example of people with mental health disorders participating in studies, when referring to power relations between the so-called crazy and normal, as well as between biomedical and social research, enables to deepen the conceptions brought by metadisciplinary regulations and to take
\end{abstract}


into account socio-economic-historical specificities of persons and/or groups of people belonging to different contexts. The challenge lies in the search for consensus in the scientific arena so that the debate on ethical care in research can stumbling advance.

Keywords: Ethics in anthropological research, vulnerability, autonomy, madness, power relations.

\section{ÉTICA EN LA INVESTIGACIÓN ANTROPOLÓGICA: LA VUL- NERABILIDAD DE LOS PARTICIPANTES CON TRASTORNOS MENTALES}

\section{Resumen}

El histórico de la reglamentación de la ética en investigación en los Estados Unidos y en Brasil permite reflexionar sobre las directrices internacionales y nacionales y, particularmente, sobre el Sistema CEP/Conep brasileño. Aunque los sistemas de revisión ética vigentes han relegado las contribuciones de las Ciencias Humanas y Sociales, ese campo del conocimiento trae una reflexión pertinente sobre el proceso de obtención del consentimiento libre y esclarecido y las expresiones de la vulnerabilidad de participantes de investigaciones científicas. El ejemplo de las personas con trastornos mentales partícipes de estudios, al referirse a las relaciones de poder existentes entre los dichos locos y normales, así como entre las investigaciones biomédica y social, posibilita profundizar las concepciones traídas por regulaciones metadisciplinares y considerar las especificidades socioeconómico-históricas de personas y/o grupos de personas pertenecientes a contextos diversos. El desafío está en la búsqueda de consensos en la arena científica para que, así, el debate sobre los cuidados éticos en la investigación pueda avanzar.

Palabras clave: Ética en la investigación antropológica, vulnerabilidad, autonomía, locura, relaciones de poder.

Flávia Siqueira Corrêa Zell

flaviacaju@hotmail.com

Érica Quinaglia Silva

equinaglia@yahoo.com.br 


\section{INTRODUÇÃO}

A Bioética pode ser entendida como um campo disciplinar capaz de acompanhar o desenvolvimento científico com respeito a valores humanos. Trata-se de uma proposta de associar biologia (em sentido amplo, como o bem-estar dos seres humanos, dos animais não-humanos e do meio ambiente) e ética (Diniz e Guilhem 2008).

Pode-se citar, como marco histórico do surgimento da Bioética, o Código de Nuremberg, formulado em 1947 em reação às atrocidades nazistas cometidas durante a Segunda Guerra Mundial, quando seres humanos foram usados como cobaias em experimentos científicos. Nesse documento, aparece a necessidade de obtenção do consentimento voluntário para a participação em pesquisas como um atestado de respeito à autodeterminação (autonomia) das pessoas. O Código de $\mathrm{Nu}$ remberg tornou-se documento básico, guia de pesquisas que envolvem seres humanos, para a quase totalidade dos países e dos centros de pesquisa médica (Brasil 2002).

Embora a criação desse documento tenha ocorrido no fim da década de 1940 , podem ser citados outros escândalos posteriores ligados a experimentos médicos. Claudia Fonseca (2015), em referência a Laura Stark (2012), apresenta alguns desses acontecimentos. No início dos anos 1950, no pós-guerra, o Centro Clínico do National Institute of Health (NIH) em Bethesda, Maryland, nos Estados Unidos, foi inaugurado, financiado pelo governo federal, com o propósi- to de realizar pesquisas científicas, para as quais procurava "pacientes sadios". Apesar de não terem doenças (pelo menos não no início da internação), esses pacientes eram submetidos a diversos experimentos na instituição durante anos. O "Programa de Cobaias" (nome mudado depois para "Programa de Normais") submetia essas pessoas, como exemplos, a doses periódicas de radiação, a injeções com soro infectado com malária e à ingestão de LSD (dietilamida do ácido lisérgico). A atração oficial era permitir que voluntários participassem da causa humanitária da medicina moderna, mas recompensas eram fornecidas, incluindo pagamento monetário (Fonseca 2015).

Embora já estivesse expresso no Código de Nuremberg, somente no ano de 1957 esse país trouxe à tona a necessidade do "consentimento informado", após a condenação de um médico perante a Justiça por não ter instruído adequadamente seu paciente dos riscos antes da realização de uma intervenção cirúrgica indicada para fins terapêuticos. Nos Estados Unidos, já existia a necessidade de obter o consentimento dos pacientes antes de qualquer procedimento, mas esse acontecimento trouxe um alerta para a necessidade da transmissão da informação pelo profissional de maneira clara e sem ambiguidades, de modo a permitir uma escolha racional entre as alternativas disponíveis para um determinado tratamento. Ademais, esse modelo, para além da prática clínica, passou a vigorar também em pesquisas científicas (Fonseca 2015). 
Houve, ainda, escândalos ligados à talidomida, uma substância usualmente utilizada como sedativo, que pode, contudo, causar má-formação fetal. Como consequência desses escândalos, em 1962, o Food and Drug Administration (FDA), órgão do governo estadunidense responsável pela fiscalização de produtos médicos e alimentícios, passou a exigir que, antes de ser lançado no mercado, todo medicamento devia passar por ensaios clínicos que comprovassem sua eficácia, bem como, após serem informadas quanto à natureza experimental dos ensaios, todas as pessoas deviam dar seus consentimentos. Todavia, a operacionalidade para a obtenção do consentimento ainda era ambígua: no Centro Clínico do NIH, por exemplo, o consentimento oral do paciente, inscrito pelo médico no registro hospitalar, já era satisfatório (Fonseca 2015).

Outro escândalo que também contribuiu para a criação de comitês de ética e a elaboração de um procedimento único para a obtenção do "consentimento informado" foi o ocorrido no Hospital Judaico de Nova Iorque, em 1964, com uma pesquisa financiada pelo NIH. Nesse experimento, era injetado soro com células cancerígenas em alguns pacientes, sem (alguns deles alegaram) que fossem esclarecidos sobre esse fato (Fonseca 2015).

A possibilidade de perda de financiamento de pesquisas do NIH, decorrente da repercussão que casos como esse provocaram, inevitavelmente comparados com as violações nazistas cometidas contra os judeus, foi o mote para a descentralização da responsabilidade ética e legal. Assim, o comitê diretor passou a exigir a criação de órgãos de deliberação grupal em hospitais ou centros de pesquisa que recebiam financiamento federal. Essa política foi formalizada por meio de um decreto em fevereiro de 1966. Qualquer pesquisa que requeresse financiamento devia ser aprovada por um grupo de "associados institucionais" quanto a três aspectos: o respeito aos direitos e ao bem-estar das pessoas envolvidas nos experimentos, a garantia da voluntariedade da participação e a análise dos riscos e dos benefícios das investigações (Fonseca 2015).

Nessa época, em 1964, a Associação Médica Mundial, reunida em Helsinque, na Finlândia, elaborou, com base no Código de Nuremberg, um documento para subsidiar as pesquisas e práticas médicas, dando origem à Declaração de Helsinque. Essa declaração não impediu, contudo, que em 1972 fosse noticiado o escândalo acontecido em Tuskegee, no Alabama, nos Estados Unidos. De 1932 a 1972, em uma pesquisa financiada pelo Serviço de Saúde Pública estadunidense, 399 pessoas negras com sorologia positiva para sífilis compuseram um grupo experimental que visava a acompanhar a história natural da doença. Essas pessoas foram deixadas sem tratamento (recebiam apenas placebo), mesmo após a descoberta da penicilina. Somente 74 participantes sobreviveram à pesquisa (Costa 2008).

Em reposta a esses acontecimentos, entre outros, o Governo e o Congresso estadunidenses instituíram, em 1974, uma comissão, a "Comissão Nacional 
para a Proteção de Sujeitos Humanos na Pesquisa Biomédica e Comportamental", encarregada de elaborar um relatório com princípios que deveriam nortear quaisquer pesquisas que envolvessem seres humanos. $\mathrm{O}$ resultado do trabalho dessa comissão, publicado em 1978, ficou conhecido como Relatório Belmont. Esse relatório enunciava três princípios para dirimir dilemas morais em pesquisas científicas: o respeito pelas pessoas, a beneficência e a justiça (Diniz e Guilhem 2008).

Em 1979, Tom Beauchamp e James Childress publicaram a obra Princípios da Ética Biomédica e, na esteira da proposta apresentada no Relatório Belmont, de cuja elaboração Beauchamp havia participado, defenderam que os conflitos morais deveriam ser mediados pela autonomia (o chamado respeito pelas pessoas), beneficência, não-maleficência e justiça (Diniz e Guilhem 2008).

Essa teoria, conhecida como principialismo, tem alguns problemas, entre os quais o idealismo universalizante, que ignora contextos socioculturais específicos, nos quais, devido a situações de desigualdade social, não é possível recorrer a tais princípios (Diniz e Guilhem 2008).

Já no início da década de 1980, a Organização Mundial da Saúde (OMS), juntamente com o Conselho de Organizações Internacionais de Ciências Médicas (CIOMS), publicou as Diretrizes Éticas Internacionais para a Pesquisa Biomédica em Seres Humanos. Trata-se de mais um documento, internacional, elaborado para nortear pesquisas científicas (Costa 2008).

Ainda no contexto estadunidense, embora os Institutional Review Boards (IRB), regulamentados pelo Departament of Health and Human Services (HHS), tivessem sido criados para resguardar, legal e financeiramente, pesquisas biomédicas, em duas ocasiões, em 1995 e 2005, houve uma “expansão sorrateira" desses comitês de ética em pesquisa, que passaram, então, a avaliar todas as pesquisas realizadas com pessoas e/ou grupos sociais, inclusive aquelas feitas no âmbito das Ciências Humanas e Sociais (Fonseca 2015).

Esse é um breve histórico da regulamentação da ética em pesquisa no cenário mundial, particularmente nos Estados Unidos, que teve influência direta no contexto brasileiro, na criação das resoluções nacionais e do atual sistema de revisão ética. A partir de uma revisão da literatura e de uma reflexão sobre as concepções trazidas por regulamentações metadisciplinares, de um lado, e as especificidades sócio-econômico-históricas de pessoas e/ou grupos de pessoas pertencentes a contextos diversos, de outro, este artigo visa a ponderar sobre o Sistema CEP/ Conep, seus avanços e seus limites.

\section{O SISTEMA CEP/CONEP}

No Brasil, a primeira regulamentação de pesquisas científicas foi elaborada na década de 1980. Em 1988, o Conselho Nacional de Saúde (CNS) editou a Resolução no 1/1988. Essa resolução constituiu um passo importante dentro da temática, mesclando questões de 
natureza ética com ações de vigilância sanitária e de biossegurança. Infelizmente, houve pouca adesão a ela, sobretudo porque restringiu-se à pesquisa médica e não previu marcos estruturais e de apoio legal para a criação e implementação de comitês, bem como para a capacitação de seus membros (Brasil 1988; Guilhem e Greco 2008).

Em 1995, o CNS nomeou um grupo de trabalho que contou com a participação da comunidade científica e da sociedade, por meio de duas audiências públicas, e, após revisão da literatura sobre o assunto e análise de documentos de diversos países, propôs a Resolução no 196/1996. Essa resolução trouxe em seu bojo os quatros referenciais da teoria principialista, com a finalidade de assegurar os direitos e os deveres que dizem respeito ao Estado, à comunidade científica e aos participantes de pesquisas. Esse documento trouxe, ainda, dois marcos importantes: a ênfase no controle social das pesquisas realizadas no país e a proteção às pessoas e grupos vulneráveis. Finalmente, é relevante mencionar que esse documento instituiu o Sistema CEP/ Conep, constituído pela Comissão Nacional de Ética em Pesquisa e pelos Comitês de Ética em Pesquisa (Brasil 1996; Guilhem e Greco 2008).

Em 2012, essa resolução foi revogada e substituída pela Resolução $\mathrm{n}^{\mathrm{O}}$ 466/2012. Essa resolução, igualmente baseada no principialismo, manteve o Sistema CEP/Conep. Algumas novidades trazidas por ela são: a possibilidade de pagamento a participantes de pesquisas clínicas de Fase I ou de bioequivalência, que são estudos em que se testa a segurança de um novo medicamento mediante o recrutamento de pessoas sadias e pesquisas que comparam um medicamento genérico ao melhor padrão existente no mercado, respectivamente; a garantia, ao final do estudo, de acesso gratuito e por tempo indeterminado aos melhores métodos profiláticos, diagnósticos e terapêuticos que se demonstrarem eficazes, no caso de pesquisas que utilizam metodologias experimentais na área biomédica; a substituição da expressão "sujeito de pesquisa" por "participante de pesquisa", que reconhece o protagonismo das pessoas que participam de pesquisas científicas; o novo entendimento do consentimento livre e esclarecido como um "processo", culminando com a assinatura de um termo específico; a inclusão, nesse processo, do assentimento livre e esclarecido, que é voltado para as pessoas consideradas legalmente incapazes; e a criação da Plataforma Brasil, que é o sistema oficial de lançamento de pesquisas científicas para apreciação de seus aspectos éticos e de monitoramento do próprio sistema (Brasil 2012; Jornal do Conselho Regional de Medicina do Estado de São Paulo 2013; Quinaglia Silva \& Portela 2017).

A Resolução no 466/2012 está em vigor até a presente data. É a norma regulamentadora que direciona as pesquisas científicas no âmbito ético, destacando no corpo do texto o respeito que o pesquisador deve nutrir em relação aos pesquisados, para que a busca do conhecimento científico seja correlacionada com o respeito à dignidade humana. 
Como nos Estados Unidos, o Sistema CEP/Conep é subordinado ao Ministério da Saúde (MS, que se assemelha ao HHS estadunidense). Nessa comparação, é importante mencionar que, apesar de a citada Resolução no 466/2012 ter sido igualmente elaborada a partir de um modelo biomédico, ela passou a ser válida para todas as pesquisas que envolvem seres humanos. Assim, depois de quatro anos de um embate científico, ético e, ainda, político, no dia 7 de abril de 2016, foi, finalmente, criada a Resolução $n^{\circ} 510$, também do CNS, do MS, que regulamenta as pesquisas nas Ciências Humanas e Sociais quanto a seus aspectos éticos (Brasil 2016). Essa resolução visa a contemplar as metodologias e especificidades éticas da pesquisa social, muito embora não haja consenso sobre sua pertinência e aplicação.

\section{A ANTROPOLOGIA E AS PESQUI- SAS COM SERES HUMANOS}

Quando se abordam pesquisas que envolvem seres humanos, é fundamental fazer uma distinção entre as pesquisas em seres humanos e as pesquisas com seres humanos. Essa diferença traduz-se no modo como a relação entre o pesquisador e as pessoas e/ou os grupos de pessoas com os quais trabalha é estabelecida pelos campos disciplinares: aquelas, nas quais há uma intervenção no objeto do conhecimento, seriam procedentes da Biomedicina (em referência a todo exercício profissional relacionado à saúde e à doença dos seres humanos, seja no campo da Medicina ou da Enfermagem, da $\mathrm{Nu}-$ trição, entre outros); estas, nas quais há uma interlocução com sujeitos de conhecimento, seriam oriundas das Ciências Humanas e Sociais (Cardoso de Oliveira 2003).

Segundo Cardoso de Oliveira (2003), haveria um "biocentrismo" na visão sobre ética, que incorreria na universalização de normas concernentes à (ética na) prática de pesquisa a partir de uma visão local (biomédica) e numa extrapolação de domínios para as demais ciências. Especificamente no campo da ética antropológica, essa visão corrobora o fato de o Código de Ética criado pela Associação Brasileira de Antropologia (ABA) no final dos anos 1980, modificado na gestão 2011/2012, não ser consultado durante a avaliação de pesquisas de antropólogos pelos CEP. Os colegiados restringem-se à consulta à Resolução nº 466/2012, que abarca prioritariamente as pesquisas $\mathrm{em}$ seres humanos, e, mais recentemente, à Resolução no 510/2016.

Nas pesquisas com seres humanos, é complicado (e mesmo indesejável) atender literalmente aos requisitos das diretrizes nacionais. Por exemplo, as pesquisas etnográficas, com observação participante, questionários, entrevistas e/ou conversas informais, são amiúde elaboradas durante a própria realização do trabalho de campo. Não há, portanto, como serem exigidas hipóteses. Tampouco é cabível preparar um instrumento de coleta de dados. As perguntas surgem durante a própria pesquisa. Ora, é isto que constitui o fazer etnográfico: uma desconstrução e reformulação de conceitos mediante a vivência com os participantes de pes- 
quisa. Se há hipóteses ou instrumentos pré-definidos, eles serão necessariamente revisitados (Quinaglia Silva \& Pereira 2016). Esses termos são, contudo, requeridos quando do preenchimento do protocolo de pesquisa na Plataforma Brasil.

Uma controvérsia específica concerne à obtenção do Termo de Consentimento Livre e Esclarecido (TCLE), questão que será aprofundada a seguir. Há, nessas pesquisas, uma relação de confiança construída entre pesquisador e interlocutor(es). Esse vínculo requer tempo, negociação, inserção do pesquisador na comunidade em que $\mathrm{o}(\mathrm{s})$ interlocutor(es) vive(m), ou seja, o consentimento é alcançado de forma paulatina e não mediante uma espécie de contrato assinado numa folha de papel, como acontece na pesquisa biomédica e é recomendado pela Resolução no 466/2012.

O liame entre a "experiência-próxima” (Geertz 2007), conformada pela empatia necessária para se traçar a confiabilidade entre pesquisador e interlocutor(es) nas pesquisas etnográficas e, assim, poder compreender a visão de mundo dele(s), e a "experiência-distante" (Geertz 2007), dada pelo distanciamento e pela tradução da realidade observada, deve ser traçado de forma cautelosa em um constante processo de negociação, que perpassa o trabalho de campo propriamente dito e a devolução dos resultados das pesquisas aos participantes delas.

Outro aspecto que deve ser destacado é a indissociabilidade, na Antropologia, entre teoria e realidade experenciada. É nesse sentido que Peirano $(2008,2014)$ concebe a etnografia não como método, mas como teoria em ação (ou teoria vivida). Essa perspectiva demonstra a dinâmica de construção desse conhecimento e a dificuldade (ou mesmo impossibilidade) de enquadramento em processos avaliativos rígidos. Ademais, considerado o encontro entre pesquisador e interlocutor(es), a postura ética, para além da observação de regulamentações metadisciplinares, também deve exaltar o combate a posturas etnocêntricas e o respeito pela diversidade cultural (Silverman 2005).

Há, portanto, diferenças teóricas e metodológicas entre as pesquisas biomédicas e as de cunho social que se refletem em especificidades éticas de cada um desses campos do conhecimento. $\mathrm{O}$ questionamento não orbita na necessidade de reflexão ética para o desenvolvimento de estudos, pois esse entendimento é pacífico e aceito entre os profissionais das diversas áreas. O desafio está na busca de consensos na arena científica, respeitadas as peculiaridades existentes nas pesquisas em e com seres humanos.

\section{O PROCESSO DE CONSENTIMEN- TO LIVRE E ESCLARECIDO}

Como já abordado anteriormente, uma das dificuldades de aplicação da Resolução no 466/2012 aos estudos antropológicos é a exigência da assinatura do TCLE. Esse instrumento deve ser livre e esclarecido, o que requer que, de um lado, os pesquisadores forneçam informação suficiente para a compreensão adequada da pesquisa proposta 
e, de outro, os participantes possam decidir livremente se aceitam ou recusam a participação no referido estudo (Rogers \& Ballantyne 2008).

$\mathrm{Na}$ Antropologia, esse processo pode ser demorado e ocorre amiúde a posteriori. Como já apontado, o consentimento, para que ocorra de forma legítima, é uma conquista buscada pelo pesquisador, resultado de um vínculo construído com o(s) interlocutor(es), fundido no dia-a-dia de desenvolvimento do trabalho de campo.

Essa prática está relacionada ao princípio do respeito pela autodeterminação das pessoas e/ou grupos sociais partícipes de pesquisas. Considera-se que os participantes de pesquisas são agentes autônomos e, como tais, são capazes de deliberar sobre questões de seu interesse.

Nesse sentido, os documentos internacionais e nacionais tornam obrigatória a obtenção do consentimento livre e esclarecido. No Brasil, a Resolução $n^{\circ}$ 466/2012 representou um avanço ao reconhecer que essa anuência faz parte de um processo, como mencionado anteriormente (Brasil 2012).

Por sua vez, a Resolução no 510/2016 admite a possibilidade de informar sobre o processo de consentimento livre e esclarecido por meio oral, do uso de língua de sinais ou outras formas que não passem necessariamente por um termo formal. Ainda, essa resolução permite comprovar o consentimento livre e esclarecido dos participantes sob a forma sonora, imagética ou por meio de testemunha, além da escrita. Finalmente, ao reconhecer que o processo de consentimento livre e esclare- cido envolve o estabelecimento de uma relação de confiança entre pesquisador e participante(s), continuamente aberta ao diálogo e ao questionamento, a Resolução no 510/2016 corrobora o entendimento antropológico de que ele pode ser obtido ou registrado em qualquer das fases de execução da pesquisa, bem como retirado a qualquer momento, sem prejuízo ao(s) participante(s) (Brasil 2016).

Esse processo de consentimento livre e esclarecido tangencia as noções de autonomia, como anteposto, e de vulnerabilidade. Essa última noção aparece na Resolução no 466/2012, que prevê a exigência do Termo de Assentimento, além do TCLE:

II.23 - Termo de Consentimento Livre e Esclarecido - TCLE - documento no qual é explicitado o consentimento livre e esclarecido do participante e/ou de seu responsável legal, de forma escrita, devendo conter todas as informações necessárias, em linguagem clara e objetiva, de fácil entendimento, para o mais completo esclarecimento sobre a pesquisa a qual se propõe participar;

II.24 - Termo de Assentimento documento elaborado em linguagem acessível para os menores ou para os legalmente incapazes, por meio do qual, após os participantes da pesquisa serem devidamente esclarecidos, explicitarão sua anuência em participar da pesquisa, sem prejuízo do consentimento de seus responsáveis legais (Brasil 2012)

A inclusão do assentimento livre e esclarecido como parte do processo de obtenção de anuências para a realiza- 
ção de pesquisas foi, sem dúvida, um avanço dessa resolução. O TCLE e o Termo de Assentimento reconhecem e concretizam a autonomia dos participantes de pesquisas. Trata-se de condição sine qua non para o ingresso em estudos. Esses termos são, assim, subsidiários aos princípios do respeito à liberdade e da expressão da vontade. Mesmo que populações consideradas vulneráveis possam ser representadas por terceiros, há de se garantir que elas sejam informadas sobre os procedimentos e que seja obtida sua aquiescência (Mello 2008).

É importante destacar que as fortalezas antepostas trazidas pela Resolução $n^{\circ}$ $510 / 2016$ sobre a informação e o registro do consentimento em qualquer fase de execução da pesquisa e por meio de diversos formatos aplicam-se igualmente ao assentimento livre e esclarecido. Essa resolução vai além, ao questionar, ainda, uma noção reificada de vulnerabilidade, substituindo-a por uma ideia de "situação de vulnerabilidade" (Brasil 2016). Essa mudança permite abarcar esse conceito dentro de contextos socioculturais específicos.

\section{EXPRESSÕES DA VULNERABI- LIDADE}

A partir de 1990, o vocábulo "vulnerabilidade" adquiriu forte notoriedade, haja vista a proliferação de documentos de caráter ético que inseriram o termo no seu escopo. Documentos importantes do mundo contemporâneo assinalam a vulnerabilidade como uma forma de angariar cuidados e precauções quanto à conduta ética, já que a vulnerabilidade estaria ligada à inca- pacidade do indivíduo de proteger os próprios interesses (Mello 2008).

É possível identificar pessoas e/ou grupos sociais que são prima facie vulneráveis devido a circunstâncias de pobreza material ou de capacidades mentais reduzidas. Outras pessoas, embora não sejam sempre vulneráveis, tornam-se em decorrência de circunstâncias específicas, como uma doença (Rogers \& Ballantyne 2008). Essa qualificação subentende que pessoas e/ou grupos sociais precisam de defesa e proteção para não serem expostos a maus-tratos, abusos e outros agravos.

A Resolução no 466/2012 define vulnerabilidade na seção II.25 como:

estado de pessoas ou grupos que, por quaisquer razões ou motivos, tenham a sua capacidade de autodeterminação reduzida ou impedi$\mathrm{da}$, ou de qualquer forma estejam impedidos de opor resistência, sobretudo no que se refere ao consentimento livre e esclarecido (Brasil 2012).

Para além de um estado, é possível entender a vulnerabilidade como função de uma relação social, cultural, política e econômica desigual. Em outras palavras, de uma relação de desigualdade pode manifestar-se a vulnerabilidade. Ela pode ser individual ou coletiva. Pode manifestar-se entre indivíduos, entre diferentes grupos, culturas ou etnias minoritárias em relação a um grupo mais amplo ou mesmo entre países. São exemplos de grupos vulneráveis mulheres, grávidas ou não, crianças, prisioneiros, refugiados, pessoas pobres e minorias étnicas (Tegan et al. 2005). 
Ayres et al. (2003) apontam para algumas indagações que ajudam a refletir sobre esse conceito: vulnerabilidade de quem? Vulnerabilidade a quê? Vulnerabilidade em que circunstâncias ou condições? Essas perguntas pressupõem diferenças entre as condições de vulnerabilidade comuns a todos e o estado de vulneração, que diz respeito à vulnerabilidade consubstanciada, e são as respostas a elas que determinarão uma justiça distributiva que atenda aos que realmente necessitam, independentemente se naquele momento encontram-se na condição de vulnerabilidade ou se pertencem a um grupo de vulneráveis, ou seja, se são vulnerados concretamente (Ayres et al. 2003).

Essa concepção é também exposta na Resolução no 510/2016, quando ela conceitua a vulnerabilidade como uma situação na qual pessoas e/ou grupos de pessoas tenham reduzida a capacidade de tomar decisões e opor resistência na situação da pesquisa, em decorrência de fatores individuais, psicológicos, econômicos, culturais, sociais ou políticos (Brasil 2016).

Assim, pessoas e/ou grupos sociais podem não ser sempre vulneráveis, mas podem se tornar vulneráveis devido a circunstâncias específicas. Daí, ser possível classificar as diferentes expressões da vulnerabilidade em vulnerabilidade intrínseca, quando causada por questões internas, e vulnerabilidade extrínseca, quando ocasionada por questões externas (Rogers \& Ballantyne 2008).

\subsection{VULNERABILIDADE INTRÍNSECA}

A vulnerabilidade intrínseca advém de características atinentes a pessoas ou populações. Nesse grupo, englobam-se: a) os bebês e as crianças; b) as crianças mais velhas e os adolescentes; c) as pessoas com deficiência mental; e d) as pessoas altamente dependentes de cuidados médicos (Rogers \& Ballantyne 2008).

A capacidade de compreender e consentir em participar de pesquisas é algo que se desenvolve gradualmente à medida que o indivíduo amadurece. Assim, são os responsáveis legais que ocupam o papel de decidir se a participação em pesquisas converge para os melhores interesses de bebês e crianças, sendo também eles os encarregados de assinar o TCLE (Rogers \& Ballantyne 2008).

Já as crianças mais velhas e os adolescentes têm direito a explicações sobre as pesquisas de que venham a participar de acordo com o nível de entendimento que apresentam. A informação deve ser, portanto, adequada à idade do potencial participante. Para além do Termo de Assentimento das crianças mais velhas e dos adolescentes, na maioria das situações, com exceção daquelas, justificadas, em que haja, por exemplo, conflitos de interesse, como no caso de pesquisas sobre violência intrafamiliar, é apropriado requerer o TCLE dos responsáveis legais, conforme estabelecido pela Resolução $n^{\circ}$ 466/2012 (Rogers \& Ballantyne 2008; Brasil 2012).

No que se refere à deficiência mental, ela influencia a habilidade de com- 
preensão das informações necessárias para dar um consentimento válido. Essa habilidade oscila de acordo com o horário do dia, da administração da medicação, da natureza da doença, dentre outros fatores. Contudo, embora os participantes de pesquisas com capacidade mental reduzida possam sofrer mais riscos se não conseguirem compreender as razões de quaisquer desconfortos ou mudanças na rotina associados à participação, isso não significa que devam ser excluídos de estudos dos quais possam se beneficiar (Rogers \& Ballantyne 2008).

Por fim, a vulnerabilidade intrínseca relacionada a pessoas altamente dependentes de cuidados médicos inclui pacientes que estão inconscientes, em unidades de tratamento intensivo ou de cuidados de alto nível, aqueles sob cuidados de emergência e alguns doentes terminais. Essas pessoas são vulneráveis à coerção porque não dispõem de tempo ou capacidade para considerar outras opções de cuidado e temem que a recusa a um convite de participação em pesquisa possa comprometer o seu tratamento. Nesses casos, além de consentimentos e assentimentos livres e esclarecidos adaptados, é necessário ponderar sobre a realização de inclusões justas e a oferta de benefícios justos (Rogers \& Ballantyne 2008).

\subsection{VULNERABILIDADE EXTRÍNSECA}

A vulnerabilidade extrínseca decorre de fatores, agentes e/ou condições externas, correlacionados ao contexto socioeconômico no qual vivem os participantes de pesquisas. Circunstâncias sociais injustas podem resultar em vul- nerabilidades. Nesse grupo de vulnerabilidade extrínseca, podem ser citadas: a) a desvantagem educacional; b) a falta de acesso a cuidados básicos de saúde; e c) a falta de poder (Rogers \& Ballantyne 2008).

A desvantagem educacional distancia os participantes de conceitos técnicos associados a pesquisas científicas, e esta falta de familiaridade, por exemplo, com os conceitos-chave da pesquisa clínica, além do analfabetismo propriamente dito podem impor obstáculos à obtenção de um TCLE adequado à população a ser pesquisada. Pessoas analfabetas ou não-escolarizadas não costumam precisar do consentimento do responsável, já que possuem a capacidade cognitiva para determinar qual curso de ação mais bem protege seus interesses. Cabe aos pesquisadores desenvolver estratégias de comunicação dos objetivos dos estudos de acordo com o grupo a ser pesquisado (Rogers \& Ballantyne 2008).

A falta de acesso a cuidados básicos de saúde também é um fator extrínseco capaz de tornar vulneráveis pessoas e/ou grupos sociais. A dificuldade de acessar serviços de saúde sobrepõe-se à vulnerabilidade intrínseca. A vulnerabilidade que acompanha a falta de recursos básicos agrava-se quando as pessoas adoecem ou precisam de cuidados de saúde, pois esta condição, combinada com a pobreza e a exclusão social, torna populações altamente suscetíveis à exploração ou à coerção em pesquisa: busca-se tratamento médico básico por meio do envolvimento em ensaios clínicos. Isso pode prejudicar a voluntariedade do consentimento dos 
participantes e levar a uma seleção injusta para a participação em pesquisas científicas (Rogers \& Ballantyne 2008).

A vulnerabilidade extrínseca ocorre, assim, quando são negados direitos sociais e políticos a certos grupos. É possível referenciá-la, então, como reflexo da "falta de poder". Essa discriminação está relacionada, entre outros fatores, a questões de classe, gênero, sexo, raça ou até mesmo a uma posição subalterna ocupada dentro de instituições. É o exemplo de pessoas pobres, mulheres, indígenas, entre outros grupos que vivem em estruturas sociais que negam seu direito à autodeterminação (Rogers \& Ballantyne 2008).

As expressões da vulnerabilidade citadas, embora requeiram o desenvolvimento de mecanismos de proteção às pessoas e/ou grupos de pessoas, não devem ser obstáculos à participação em pesquisas. Para tanto, conforme já mencionado, uma das estratégias de legitimação da escuta dessa população ocorre pela obtenção do consentimento e/ou do assentimento livre e esclarecido.

\section{A VULNERABILIDADE E A LOU- CURA NA PESQUISA ANTROPO- LÓGICA}

Embora a classificação entre vulnerabilidades intrínseca e extrínseca seja útil para refletir sobre as expressões que a vulnerabilidade pode tomar, esse quadro é simplista na medida em que pode desconsiderar as relações construídas entre indivíduos e os grupos a que pertencem.

O exemplo das pessoas com transtor- nos mentais é pertinente para ilustrar essa crítica. Essas pessoas poderiam ser consideradas intrinsecamente vulneráveis. De fato, quando da realização de pesquisas com elas, deve-se tomar cuidados para protegê-las de riscos potenciais. A depender do caso concreto, da doença, da medicação e mesmo do dia, essas pessoas podem ter sua autonomia reduzida para decidir livremente se aceitam ou não participar de pesquisas científicas. Assim, estratégias devem ser buscadas pelo pesquisador para que haja comunicação adequada e esclarecimento satisfatório para essa tomada de decisão.

Para além desses cuidados éticos, outra questão é relevante: essas pessoas não são apenas vulneráveis por possuírem transtornos mentais. É preciso deslocar o entendimento da loucura do indivíduo para a sociedade (e toda a conjuntura que cria a própria loucura e a consequente exclusão dos loucos). Essa reflexão possibilita extrapolar o quadro fechado das classificações antepostas e atribuir à sociedade a responsabilidade pela criação de mecanismos de adoecimento e exclusão.

As perspectivas organicista, que encara a loucura como um distúrbio fisiológico, e psicofuncional, que considera a loucura como uma desorganização da personalidade, são insuficientes para dar conta da amplitude desse fenômeno. Para além de um processo físico e/ou mental, a loucura é relacional, não podendo ser definida em si mesma, como um fato isolado: a loucura é interior à razão. A loucura não está localizada no indivíduo, mas revela algo do meio no qual emerge. Essa concepção só pode ser entendida, portanto, 
a partir do entendimento correspondente de normalidade socialmente estabelecido. Além de relacional, a loucura é relativa ao contexto social e ético no qual é elaborada: a loucura e as suas manifestações não são as mesmas a depender das coletividades humanas. Nesse sentido, um indígena pode ser considerado um xamã enquanto um paulistano, um doente mental (Frayze-Pereira 1994).

Para Sigmund Freud (1997), o mal- estar na civilização (ocidental) adviria justamente da árdua tarefa de encontrar um equilíbrio entre indivíduo e sociedade. Essa relação conflituosa seria, para esse autor, uma das principais causas do sofrimento psíquico.

Destarte, a loucura pode ser considerada como algo inerente a pessoas, decorrente de transtornos físicos e/ ou mentais, mesmo que não existam marcadores biológicos para a assertiva de um laudo conclusivo sobre as perspectivas organicista e psicofuncional, bem como resultado de relações de poder sobre corpos desviantes, tratados como subalternos. À vulnerabilidade intrínseca soma-se uma vulnerabilidade extrínseca dessa população.

Edward Said (1992) traz um importante aporte ao debate sobre as formas de produzir conhecimento a partir da denúncia das assimetrias globais de poder, já que as relações de dominação por meio do saber-poder sempre estiveram presentes entre o Ocidente e o Oriente, existentes também nos liames entre "normais" e "loucos". A discussão proposta por esse autor permeia as conexões entre essas categorias e as consequências dos diferenciais de po- der para a situação econômica, social e cultural dos loucos em diferentes lugares e períodos da história, marcando a proeminência e a característica constitutiva da situação de vulnerabilidade de indivíduos e/ou grupos subalternizados.

Essa mirada é importante porque mostra que é também uma postura ética assumir opressões histórica, social e simbolicamente construídas e impedir doravante o silenciamento dessa população (e de outros grupos sociais) em nome de uma suposta proteção.

\section{ALGUNS APONTAMENTOS}

A participação de seres humanos em pesquisas foi marcada pela submissão de grupos desprotegidos, institucionalizados, discriminados por sua classe, raça ou etnia, dentre outros fatores, com ausência de respeito à dignidade humana. Essas pessoas foram tidas como objetos em prol do avanço da ciência, sem poder exercer sua autonomia de decisão. Relações de poder contribuíram para a ocorrência de injustiças no campo dessas pesquisas. Daí, a necessidade de elaboração de diretrizes éticas para evitá-las. $\mathrm{O}$ poder, por ser coercitivo, restringe a liberdade de reflexão crítica, podendo abalar o exercício da ética.

Quando se observam as pesquisas no campo da Biomedicina verifica-se um registro de atrocidades e atitudes desumanas praticadas mesmo por aqueles cujo juramento perpassa a ideia de "salvar vidas", os médicos. Detentores de poderes técnico e científico, protegidos 
pelo escudo da ciência, eles cometeram arbitrariedades para com os que estavam na outra margem da relação.

Diretrizes éticas internacionais, como o Código de Nuremberg, a Declaração de Helsinque e as Diretrizes Éticas Internacionais para a Pesquisa Biomédica em Seres Humanos, além de documentos nacionais, como as Resoluções $\mathrm{n}^{\circ}$ 466/2012 e 510/2016, são referências incontestáveis para assegurar o respeito à autonomia das pessoas e/ou grupos sociais participantes de pesquisas. Apesar de existirem lacunas, apresentaram avanços para o debate ético que envolve o desenvolvimento científico.

Todos os participantes são concreta ou potencialmente vulneráveis e devem, pois, receber proteção contra danos advindos de pesquisas. Como parte dessa proteção, deve haver convocação à participação nas decisões tomadas. É dever do Estado zelar pela dignidade de seus cidadãos. É dever da comunidade científica realizar suas pesquisas em consonância com as diretrizes estabelecidas nas referidas normativas. E é dever da sociedade realizar o controle social do conhecimento produzido. A pesquisa deve ser encarada como aliada da sociedade, pois é uma das formas de promover o avanço do conhecimento e possibilitar a geração de benefícios que se reverterão para ela própria.

Relações de poder também são encontradas na arena científica. No debate sobre a regulamentação da ética em pesquisa nos Estados Unidos, no Brasil e alhures, as Ciências Humanas e Sociais foram amiúde negligenciadas. No campo específico da Antropolo- gia, as reflexões trazem uma crítica a processos avaliativos rígidos e modelos dogmáticos, ao apontar para questões sociais que emergem de situações de pesquisa. O exemplo da vulnerabilidade de pessoas com transtornos mentais é pertinente para ampliar, aprofundar e extrapolar as concepções trazidas por regulamentações metadisciplinares e atentar para especificidades sócio-econômico-históricas de pessoas e/ ou grupos de pessoas pertencentes a contextos diversos.

Esse "modo de fazer" antropológico traz, portanto, contribuições aos sistemas de revisão ética vigentes. Particularmente no Brasil, as Ciências Humanas e Sociais, em geral, questionam o alcance do poder centralizado do Sistema CEP/Conep e a burocratização que ele gera. A pesquisa social mostra um desafio aos demais campos do conhecimento: é necessário, a partir da atenção às especificidades de cada um deles, construir consensos. Dessa forma, o debate sobre os cuidados éticos na pesquisa poderá tropegamente avançar.

\section{REFERÊNCIAS}

Ayres, J. R. C., Júnior, I. F., Calazans, G. J. e Filho, H. C. S. 2003. O conceito de vulnerabilidade e as práticas de Saúde: novas perspectivas e desafios, in Promoção da Saúde: conceitos, reflexões, tendências. Organizado por Czeresnia, D., Freitas, C. M. Rio de Janeiro: Editora Fiocruz.

Brasil. Ministério da Saúde. Conselho Nacional de Saúde. 2002. Manual operacional para comitês de ética em pesquisa. Brasília: Ministério da Saúde. Disponível em: http:// 
conselho.saude.gov.br/biblioteca/livros/ Manual ceps.pdf. Acesso em: 4 de outubro de 2017.

Brasil. Resolução no 1 , de 13 de junho de 1988, do Conselho Nacional de Saúde, do Ministério da Saúde. Diário Oficial da União 1988; 13 jun.

Brasil. Resolução no 196, de 10 de outubro de 1996, do Conselho Nacional de Saúde, do Ministério da Saúde. Diário Oficial da União 1996; 10 out.

Brasil. Resolução no 466, de 12 de dezembro de 2012, do Conselho Nacional de Saúde, do Ministério da Saúde. Diário Oficial da União 2012; 12 dez.

Brasil. Resolução no 510 , de 7 de abril de 2016, do Conselho Nacional de Saúde, do Ministério da Saúde. Diário Oficial da União 2016; 7 abr.

Cardoso de Oliveira, Luís Roberto. 2003. Pesquisas em vs. Pesquisas com seres humanos. Série Antropologia 1(336).

Costa, Sérgio. 2008. O desafio da ética em pesquisa e da bioética, in Ética em pesquisa: temas globais. Organizado por Diniz, Debora, Sugai, Andréa, Guilhem, Dirce e Squinca, Flávia. Brasília: LetrasLivres; Editora UnB.

Diniz, Debora e Guilhem, Dirce. 2008. O que é bioética. São Paulo: Editora Brasiliense.

Fonseca, Claudia. 2015. Situando os comitês de ética em pesquisa: $\mathrm{O}$ sistema CEP (Brasil) em perspectiva. Horizontes Antropológicos 21(44): 333-369.

Frayze-Pereira, João Augusto. 1994. O que é loucura. São Paulo: Brasiliense.

Freud, Sigmund. 1997. O mal-estar na civilização. Rio de Janeiro: Imago Editora.

Geertz, Clifford. 2007. O saber local: novos ensaios em antropologia interpretativa. Petrópolis, RJ: Vozes.

Guilhem, Dirce e Greco, Dirceu. 2008. Said, Edward. 1992. O orientalismo revis-
A Resolução CNS 196/1996 e o Sistema CEP/Conep, in Ética em pesquisa: temas globais. Organizado por Diniz, Debora, Sugai, Andréa, Guilhem, Dirce e Squinca, Flávia. Brasília: LetrasLivres; Editora UnB.

Jornal do Conselho Regional de Medicina do Estado de São Paulo (Cremesp), Edição 305 - 07/2013. Disponível em: http://www.cremesp.org. $\mathrm{br} /$ ? siteAcao $=$ Jornal\&id $=1764 . \quad$ Acesso em: 19 de janeiro de 2017.

Mello, Daisy Giffoni de. 2008. A vulnerabilidade e suas relações com a autonomia e a pesquisa com seres humanos. Dissertação de Mestrado em Ciências, Escola Nacional de Saúde Pública, Fundação Oswaldo Cruz, Rio de Janeiro [ENSP]. Disponível am/icict/5434/2/1033.pdf. Acesso em: 4 de outubro de 2017.

Peirano, Mariza. 2008. Etnografia, ou a teoria vivida. Revista do núcleo de antropologia urbana da USP 2: 1-10.

Peirano, Mariza. 2014. Etnografia não é método. Horizontes Antropológicos 20(42): 377-391.

Quinaglia Silva, Érica e Pereira, Éverton Luís. 2016. Ética em pesquisa: os desafios das pesquisas em ciências humanas e sociais para o atual sistema de revisão ética. Revista Anthropológicas 27(2): 120-147.

Quinaglia Silva, Érica e Portela, Soraya Christina Oliveira. 2017. Ética em pesquisa: análise das (in)adequações do atual sistema de revisão ética concernentes à pesquisa social. Revista Mundaú 2: 38-53.

Rogers, Wendy e Ballantyne, Angela. 2008. Populações especiais: vulnerabilidade e proteção, in Ética em pesquisa: temas globais. Organizado por Diniz, Debora, Sugai, Andréa, Guilhem, Dirce e Squinca, Flávia. Brasília: LetrasLivres; Editora UnB. em: https://www.arca.fiocruz.br/bitstre- 
to, in Pós-modernismo e política. Editado por Hollanda, Heloisa Buarque de, pp. 251273. Rio de Janeiro: Rocco.

Silverman, S. 2005. The Boasins and the invention of cultural anthropology, in Barth, F. et al. One discipline, four ways: British, German, French, and American Anthropology, pp. 257-274. Chicago: The University of Chicago Press.

Tegan, Cristiana, Venâncio, Paulo César, Marcondes, Fernanda Klein, Rosalen, Pedro Luis. 2005. Autonomia e vulnerabilidade do sujeito da pesquisa. Revista de Direito Sanitário 6 (1/2/3): 25-37. Disponível em: http://www.revistas.usp.br/rdisan/article/download/80812/84459. Acesso em: 4 de outubro de 2017. 